\title{
Implementasi Pemberdayaan Masyarakat Miskin melalui Family Development Session (FDS) pada Program Keluarga Harapan (PKH)
}

\section{Implementation of Empowerment of the Poor through Family Development Session (FDS) in the Family Hope Program (PKH)}

\author{
Budhi Rahardjo ${ }^{1,}$ Suryo Ediyono ${ }^{2}$, Desy Kurnia Putri ${ }^{3}$ \\ Program Doktor Penyuluhan Pembangunan/Pemberdayaan Masyarakat, \\ Universitas Sebelas Maret Surakarta ${ }^{1,2,3}$ \\ Email : budhirahardjo8@gmail.com
}

\begin{abstract}
The graduation rate of Benefit Recipient Family (KPM) in Manang Village,Grogol Sub-district is zero even though there is already a Family Development Session (FDS) which is an implementation of empowerment activities in Program Keluarga Harapan (PKH) in the form of community learning process expected to increase the independence and welfare of Benefit Recipient Family (KPM). In general, this study aims to determine the implementation of the process and barriers of empowerment through Familly Development Session of Program Keluarga Harapan (PKH) in Manang Village.

This research is a qualitative descriptive, case study approach, conducted in August involved 7 informants. Data collection was carried out by interview, observation, and documentation. Types and sources of data in the form of primary and secondary data were selected by purposive sampling. The researcher used the Miles and Huberman method for data analysis method.

The result of this research is the empowerment of the Family Development Session that has been running since 2017, supporting factor of Family Development Session implementtation is the Guider of PKH had beed train but obstacle of Family Development Session is the material transformation stage which is not optimal because the FDS implementation time is short, and there is an inaccuracy between the provided Familiy Development Session's material with the needs of Benefit recipient family.

It is recommended to related parties among social services, Coordinators, and fasilitators of $(\mathrm{PKH})$ to supervise the implementation of Family Development Session in accordance with applicable regulations. For Benefit Recipirnt Family should remember their duty as the member of First Coditional Cash Transfer (PKH).
\end{abstract}

Keywords: Poor Community Empowerment, Family Development Session(FDS), Program Keluarga Harapan $(\mathrm{PKH})$

\begin{abstract}
ABSTRAK
Tingkat graduasi KPM PKH di desa Manang Kecamatan Grogol adalah nol padahal sudah ada Family Development Session (FDS) yang merupakan implementasi kegiatan pemberdayaan dalam PKH berupa proses belajar masyarakat yang diharapkan dapat meningkatkan kemandirian dan kesejahteraan KPM. Secara umum penelitian ini bertujuan untuk mengetahui implementasi proses dan hambatan pemberdayaan FDS PKH di Desa Manang.

Penelitian ini adalah deskriptif kualitatif, dengan pendekatan studi kasus, dilaksanakan pada bulan Agustus dengan informan 7 orang. Pengumpulan data dilakukan dengan wawancara mendalam, observasi, dan dokumentasi. Jenis dan sumber data berupa data primer dan sekunder dipilih secara purposive sampling. Metode analisis data menggunakan metode Miles dan Huberman.

Hasil penelitian ini adalah pemberdayaan FDS sudah berjalan sejak 2017, faktor pendukung implementasi FDS adalah pendamping PKH yang sudah didiklat sedangkan hambatan FDS adalah pada tahap transformasi materi yang tidak maksimal karena waktu pelaksanaan FDS yang singkat, dan ada ketidaktepatan materi FDS yang diberikan dengan kebutuhan KPM.

Disarankan pihak terkait baik Dinas Sosial, Koordinator dan Pendamping PKH terus bekerja dan memantau pelaksanaan FDS PKH sesuai peraturan yang berlaku. Bagi KPM selalu mengingat kewajibannya sebagai peserta $\mathrm{PKH}$.
\end{abstract}


Kata Kunci : Pemberdayaan Mayarakat Miskin, FDS, PKH

\section{PENDAHULUAN}

PKH di Indonesia menjadi primadona dalam penanganan kemiskinan terbukti program ini berlangsung cukup lama dari tahun 2007 sampai sekarang dengan peningkatan jumlah keluarga penerima manfaat (KPM) yang sangat banyak, sekarang berjumlah 10 juta KPM. Guna mendukung efektivitas pelaksanaan Program Keluarga Harapan dan penguatan bagi Keluarga Penerima Manfaat PKH, pada tahun 2017 Kemensos merancang suatu kegiatan yang dinamakan Pertemuan Peningkatan Kemampuan Keluarga (P2K2) atau disebut juga dengan Family Development Session (FDS) yang merupakan proses belajar peserta PKH berupa pemberian dan pembahasan informasi praktis di bidang kesehatan, pendidikan, ekonomi, perlindungan anak, lansia, dan disabilitas, yang disampaikan melalui pertemuan kelompok bulanan. Tujuan utama dari FDS adalah menciptakan perubahan perilaku positif dan kemandirian KPM agar dapat digunakan dalam peningkatan kesejahteraan keluarga dan masyarakat (Dirjen Linjamsos, 2020: 10).

Keberhasilan PKH dapat dibuktikan dengan tingkat graduasi/ kelulusan KPM PKH menurut Permensos RI Nomor 1 tahun 2018 tentang Program Keluarga Harapan (PKH), graduasi PKH adalah berakhirnya masa kepesertaan KPM PKH, meskipun program PKH sendiri masih berlangsung. Jika kondisi KPM dinilai telah mandiri secara ekonomi dan atau tidak lagi memenuhi syarat kondisional sebagai KPM PKH maka KPM tersebut akan graduasi. Umumnya, mereka memiliki usaha yang dirintis dari skala kecil namun telah berjalan lancar.

Penerima PKH di Kabupaten Sukoharjo sebanyak 27.518 KPM, pada Program Keluarga Harapan satu KPM adalah satu Keluarga yang berada dalam satu KK (Sekretariat PPKH Kab. Sukoharjo, 2020).

Kecamatan Grogol sebagai penerima PKH tertinggi di Kabupaten Sukoharjo yaitu 3.045 KPM, akan tetapi tingkat graduasi/ kelulusan PKH terendah,yaitu 18 KPM. Sedangkan jumlah penerima PKH terendah di Kabupaten Sukoharjo adalah Kecamatan Gatak, dengan tingkat graduasi lebih banyak yaitu 20 KPM.

Berdasarkan data tersebut maka fokus lokasi penelitian yang dipilih adalah di Desa Manang Kecamatan Grogol karena dari 139 KPM PKH di Desa Manang, tingkat graduasinya adalah terendah dibanding desa lainnya, yaitu 0 (nol). Berdasarkan latar belakang di atas, teori yang akan digunakan peneliti adalah Teori Tahapan Pemberdayaan Masyarakat yakni menjelaskan berbagai tahapan pemberdayaan yang dibagi menjadi 3 tahapan, yaitu pertama tahap penyadaran dan pembentukan perilaku, kedua tahap trasnformasi kemampuan, ketiga tahap peningkatan kemampuan intelektual, kecakapan, dan keterampilan Sulistyani (2017: 83).

Berdasarkan uraian tersebut maka tujuan penelitian ini adalah untuk mengetahui implementasi pemberdayaan masyarakat miskin melalui FDS PKH di Desa Manang Kecamatan Grogol Kabupaten Sukoharjo.

\section{METODE}

Jenis penelitian yang digunakan adalah deskriptif kualitatif dengan pendekatan 
studi kasus. Penelitian ini dilakukan pada bulan Agustus 2020 di Desa Manang Kecamatan Grogol Kabupaten Sukoharjo. Informan penelitian adalah orang yang dimanfaatkan untuk memberikan informasi tentang situasi dan kondisi latar belakang penelitian (Moleong 2010). Informan penelitian ini terdiri dari 7 orang, yaitu 1 Koordinator PKH Kecamatan Grogol, 1 Pendamping Sosial PKH, dan 5 orang KPM/ penerima manfaat PKH Desa Manang. Teknik pengumpulan data pada penelitian kualitatif dapat dilakukan dengan cara participant observation, indept interview, dokumentasi, tringulasi/ gabungan (Sugiyono, 2020:105).

Teknik analisa data dilakukan melalui beberapa tahapan sesuai dengan teori Miles dan Huberman dalam Sugiyono (2020: 133), yang mengemukakan bahwa aktivitas analisis data kualitatif dilakukan secara interaktif dan berlangsung secara terus menerus sampai tuntas, sehingga datanya sudah jenuh. Aktivitas dalam analisis data, terdiri dari Data Reduction, Data Display Conclusion drawing/ Verification. Penyajian kutipan langsung dilakukan dalam bentuk bahasa yang tidak formal, dalam susunan kalimat sehari-hari dan pilihan kata atau konsep asli informan. Berdasarkan pernyataan dari informan tersebut kemudian dikaji dengan teori yang telah dipilih.

\section{HASIL DAN PEMBAHASAN}

Paparan hasil penelitian ini berupa deskripsi kasus atau pengalaman masingmasing subjek yang sifatnya komprehensif, mendalam, dan menyeluruh. Hasil penelitian ini bersumber dari hasil wawancara mendalam, observasi langsung dan dokumentasi. Berikut hasil penelitian ini :

\section{Implementasi Pemberdayaan Masyarakat Miskin melalui FDS PKH di Desa Manang Kecamatan Grogol}

Pada tahap penyadaran dan pembentukan perilaku, sebelum mulai pemberdayaan FDS pendamping PKH mereview materi yang telah diberikan bulan lalu untuk mengingatkan kembali dan sebagai kroscek kepada KPM apakah yang dipelajari bulan lalu sudah dipraktekkan KPM di rumah. Hal ini telah sesuai dengan teori Sulistyani (2017:83) tentang tahapan pemberdayaan pada tahap penyadaran dan perubahan perilaku, disini pendamping sebagai komunikator melakukan upaya agar KPM sadar dan tahu akan materi yang diberikan sehingga dapat merubah perilaku KPM kearah yang lebih baik. Namun pada kenyataannya saat peneliti melakukan observasi langsung hanya satu KPM saja yang mampu bercerita materi yang lalu, dan tidak ada yang mempraktekkan di rumah.

Tahap transformasi kemampuan berupa wawasan pengetahuan, kecakapanketrampilan. Berdasarkan observasi langsung yang dilakukan peneliti, pada saat pemberdayaan pendamping menggunakan bahasa daerah yang mudah dimengerti, setelah selesai pembelajaran FDS pendamping PKH mereview ulang materi yang telah diberikan tetapi hanya sedikit yang bisa menjawab. Kemudian sebelum pulang pendamping $\mathrm{PKH}$ juga memberikan pesan agar bisa dipraktekan di rumah, tetapi ada beberapa peserta yang menjawab iya mudah-mudahan tidak lupa. Hal tersebut tidak sesuai dengan teori pemberdayaan Sulistiyani (2017:83) pada tahap transformasi karena respon peserta yang terlihat tidak paham akan materi yang diberikan.

Tahap peningkatan kemampuan intelektual, kecakapan-ketrampilan sehingga terbentuklah inisiatif dan kemampuan inovatif untuk mengantarkan pada kemandirian. Berdasarkan observasi langsung selesai penyampaian materi FDS pendamping mereview ulang materi yang tadi sudah disampaikan tetapi respon peserta sangat kurang, ditambah saat peneliti melakukan wawancara langsung terdapat pernyataan 
KPM yang tidak bisa mundur dari PKH karena belum dapat mandiri dan belum sukses usahanya. Hal tersebut tidak sesuai dengan teori pemberdayaan Sulistiyani (2017:83) pada tahap peningkatan kemampuan kecakapan -ketrampilan, karena tidak tebentuk inisiatif dan kemampuan inovatif untuk mengantarkan pada kemandirian.

\section{Faktor pendukung Implementasi Pemberdayaan Masyarakat Miskin melalui FDS PKH di Desa Manang Kecamatan Grogol}

Berdasarkan wawancara mendalam dan observasi langsung bahwa salah satu faktor pendukung implementasi FDS di Desa Manang adalah pendamping PKH sebagai pelaksana FDS yang sudah terlebih dahulu didiklat, hal ini dinyatakan sendiri oleh Koordinator PKH Kecamatan Grogol "Pendamping pelaksana FDS juga harus didiklat terlebih dahulu karena kan pendamping itu backgrtound pendidikannya beda-beda jadi perlu di diklat agar dalam pelaksanaan FDS sesuai dengan prosedur" (Wawancara pada 13 Agustus 2020).

Hal tersebut sesuai dengan teori Menurut Dirjen Linjamsos RI tahun 2019 dimana diklat FDS yang diadakan oleh Balai Diklat Kemensos RI merupakan salah satu kebijaksanaan pemerintah dalam mendukung implementasi pemberdayaan masyarakat melalui FDS. Hal ini sesuai dengan teori faktor pendukung pemberdayaan menurut Soekidjo Notoatmodjo (2010:9) bahwa kebijaksanaan-kebijaksanaan pemerintah, baik yang dikeluarkan melalui perundang-undangan, peraturan- peraturan pemerintah, suratsurat keputusan menteri dan pejabat pemerintah, dan sebagainya adalah merupakan arahan yang harus diperhitungkan oleh organisasi dalam pengembangan sumber daya manusia.

\section{Hambatan Pemberdayaan Masyarakat Miskin melalui FDS PKH di Desa Manang Kecamatan Grogol}

Hambatan dalam pemberdayaan FDS di desa Manang berdasarkan hasil observasi langsung dan wawancara mendalam dengan informan adalah waktu pertemuan kurang efektif karena terlalu sore, sehingga peserta tidak fokus, hal ini sesuai dengan teori hambatan pemberdayaan menurut Ibrahim (2010:122) tentang kurang tepatnya perencanaan atau estimasi. Selain itu karena waktu yang singkat membuat pendamping tidak bisa menjelaskan semua materi yang ada di modul, untuk alat/media FDS masih ada yang kurang mendukung. Lalu berdasarkan wawancara dengan KPM, mereka mengatakan sulit menerima materi karena banyak pikiran, entah itu tentang rumah maupun pekerjaan. Hal ini sesuai dengan teori hambatan pemberdayaan menurut Ibrahim (2010:122) bahwa adanya konflik dan motivasi, disebabkan karena adanya masalah-masalah pribadi dapat menghambat proses pemberdayaan. Namun sebenarnya ada materi FDS yang KPM ingin pendamping menjelaskan tetapi belum ada penjelasan tentang materi tersebut, jadi ada ketidaktepatan materi yang dijelaskan pendamping dengan materi yang sebenarnya dibutuhkan KPM, selain itu ada pula KPM yang mengatakan belum bisa mundur secara mandiri sejahtera dari PKH karena merasa masih membutuhkan dan belum sukses usahanya. Pernyataan tersebut membenarkan bahwa tujuan dari implementasi program FDS PKH belum terwujud, dimana tujuannya adalah untuk kemandirian dan kesejahteraan KPM yang ditunjukkan dengan graduasi mandiri sejatera. Namun untuk saat ini di Desa Manang belum ada KPM yang mundur dari PKH secara sukarela. 


\section{KESIMPULAN}

Implementasi pemberdayaan pada Program Keluarga Harapan di desa Manang Kecamatan Grogol dilakukan melalui pertemuan FDS dengan materi/ modul yang beragam. Kegiatan pemberdayaan FDS dilakukan dalam bentuk kegiatan pembelajaran dimana pendamping sebagai penyampai materi. Pelaksanaan FDS sudah rutin dilaksanakan satu bulan sekali namun pada penelitian terdapat ketimpangan dimana pendamping dalam menyampaikan materi tidak sesuai dengan langkah- langkah di modul FDS, kemudian materi yang diberikan pendamping tidak sesuai dengan apa yang dibutuhkan KPM/ peserta PKH, sehingga membuat tujuan FDS belum tercapai. Faktor pendukung pelaksanaan FDS PKH adalah pendamping PKH sebagai pelaksana / komunikator FDS yang sudah di diklat oleh Balai Diklat. Hambatan dalam pemberdayaan melalui FDS PKH di Desa Manang yaitu yang pertama waktu pertemuan kurang efektif, kedua alat/media FDS masih ada yang kurang mendukung, ketiga kesadaran KPM untuk sukarela mundur dari PKH sangat kurang.

\section{SARAN}

Berdasarkan hasil penelitian Implementasi Pemberdayaan Masyarakat Miskin melalui Family Development Session pada Program Keluarga Harapan di Desa Manang Kecamatan Grogol Kabupaten Sukoharjo, maka saran yang dapat diberikan oleh peneliti adalah sebagai berikut:

1. Bagi Dinas Sosial diharapkan terus melakukan pemantauan dan pengawasan terhadap program PKH dan pelaksanaan kegiatan FDS dengan harus sering terjun ke lapangan melakukan pemantauan terhadap jalannya program ini.

2. Bagi Koordinator PKH agar lebih intens komunikasi dan melakukan pengawasan terhadap kinerja pendamping $\mathrm{PKH}$, sebaiknya dilakukan monitoring dan evaluasi setiap bulan setelah pelaksanaan FDS. Bila perlu melakukan pengawasan langsung saat pendamping melaksanakan FDS.

3. Bagi Pendamping PKH diharapkan terus melaksanakan tugasnya sesuai dengan perarturan, serta selalu meningkatkan kemampuannya terutama dalam hal komunikasi sehingga pelaksanaan FDS PKH dapat mencapai tujuannya. Melakukan terobosan untuk mengaktifkan motivasi dan antusias KPM dalam mengikuti kegiatan pemberdayaan FDS, dapat berupa mengadakan perlombaan antar dusun/ antar kelompok dengan tema FDS/ sesuai modul yang ada di dalam FDS.

4. Bagi Masyarakat terutama Keluarga Penerima Manfaat (KPM) PKH diharapkan untuk tetap mengikuti arahan yang diberikan pendamping $\mathrm{PKH}$, lebih aktif saat kegiatan pemberdayaan FDS, dan lebih memperhatikan kewajibannya dalam PKH agar tujuan untuk kehidupan yang lebih mandiri sejahtera dapat segera tercapai.

\section{DAFTAR PUSTAKA}


Dinas Sosial Kab. Sukoharjo. 2020. DTKS Januari Tahun 2020.

Dirjen Linjamsos. 2019. Pedoman Pelaksanaan PKH Tahun 2019. Jakarta: Kementerian Sosial RI.

$$
\text { . 2020. Petunjuk Pelaksanaan Pertemuan Peningkatan }
$$
Kemampuan Keluarga (P2K2). Jakarta: Kementerian Sosial. . 2020. Petunjuk Teknis Penyaluran Bantuan Sosial Non Tunai Program Keluarga Harapan Tahun 2020. Jakarta: Kementerian social

Ibrahim. 2010. Inovasi Pendidikan. Jakarta: Departemen Pendidikan dan Kebudayaan P2LPTK.I

Moelong, L. 2010. Metode Penelitian Kualitatif. Bandung. PT. Remaja Rosdakarya.

Notoatmodjo, Soekidjo. 2010. Ilmu Perilaku Kesehatan. Jakarta. Rineka Cipta. Sekretariat PPKH Kab. Sukoharjo. 2020. SPM FC KPM PKH Tahap 3 tahun 2020. Sugiyono. 2020. Metode Penelitian Kualitatif. Bandung : Alfabeta.

Sulistyani, A T. 2017. Kemitraan dan Model-Model Pemberdayaan. Yogyakarta : Gavamedia. 